\title{
Research on the Improvement of Calculation Method for the Interference Assembly of Locomotive Traction Gear
}

\author{
Tianmin Guan¹, Meichao Qin, ${ }^{1}{ }^{*}$, Lei Lei ${ }^{1}$ \\ 1 Department of Mechanical Engineering, Dalian Jiao Tong University, P. O. B. 289\#, 116000 Dalian, Liaoning Province, China \\ 2 CRRC DALIAN CO., LTD., P. O. B. 272\#, 116021 Dalian, Liaoning Province, China \\ * Corresponding author, e-mail: qmcdalian@126.com
}

Received: 31 October 2018, Accepted: 05 May 2019, Published online: 10 September 2020

\begin{abstract}
The interference assembly is the main method for the connection between the traction gear and the shaft. The selection of the interference plays a critical role in the design of the traction gear. The traditional method of the calculation of the interference of the traction gear oversimply the mathematical model. The error goes out of the acceptable range so that the old method is not suitable for the design of the web structure. In this paper we propose an improved algorithm for solving the interference of the traction gear by combining the classical elastic mechanics theory and the finite element segmentation technique. The results from our improved algorithm is compared with that from the traditional method and the finite element simulation data is compared with the experimental results. Both comparisons verified the rationality and the feasibility of our algorithm. Our research provides the theoretical reference significance and practical guiding value for the selection of the range of interference.
\end{abstract}

Keywords

traction gear, web structure, interference, finite element analysis, press fitting

\section{Introduction}

Interference fit is a common component assembly method in the field of mechanical engineering. The coupling between the traction gear and the shaft of the locomotive is mainly applied by interference connection. The interference quantity of the gear assembly plays a critical role in gear design. The interference design should not only satisfy the gear transmission torque, but also meet the requirements that the plastic deformation does not occur on the gear materials. The traditional method is to model the gear as a cylinder for calculation, which might cause unacceptable error, since the locomotive traction gear, especially the driven gear, adopts the forging web structure (as shown in Fig. 1). In this paper, we apply segmented calculation method based on the traditional interference calculation method and the characteristics of gear structure. A new design way for the interference fit of web structure cylinder is proposed. Our calculation method is verified by the finite element analysis and the pressure and the anti-pressure experiments.

\section{The principle of determining the amount of interference}

The calculation of the interference is an important part of the design of the traction gear of the locomotive. The reasonableness of the interference design will directly affect the running safety of the locomotive. The interference fit between the traction gear and the shaft needs to meet the minimum combination pressure required for the transmission of traction. In addition, the setting of the

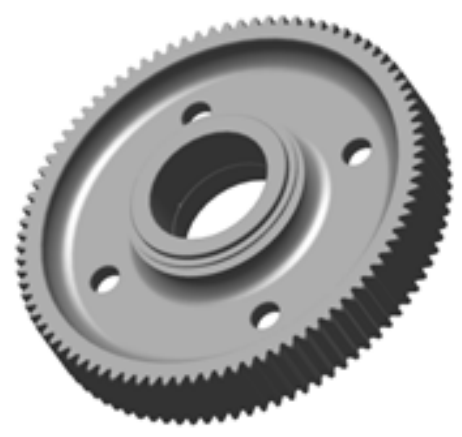

Fig. 1 Locomotive traction gear 
interference should avoid the plastic deformation of the joint. The determination of the interference of the traction gear of the locomotive is mainly determined by the effective transmission loading and a certain safety margin that could ensure a large material reserve between the gear and the axle, and a simple press-fit process. That is to say, we are supposed to select the smallest possible amount of interference for traction gear assembly under the premise of ensuring the safety of driving (Eyercioglu et al., 2009).

\section{Locomotive traction gear interference design}

\subsection{The working conditions for interference calculation}

From the safety point of view, the maximum starting traction torque is used as the basis for determining the minimum effective interference of the joint. Due to the unique characteristics of the driven gear web structure, here we define two geometric dimension parameter: the root diameter $d_{a 1}$ and the Wheel outer diameter $d_{a 2}$. And the theoretical combination length $L$ is divided into two parts, as shown in Fig. 2.

The locomotive traction force $F$ generated by the motor is transmitted to the driving gear, driven gear, and wheel via axle in order. The efficiency $i$ of the axle box bearing and the rolling bearing are both 0.98 . The transmitted torque $T$ of driven gear under the working condition when starting can be expressed as Eq. (1):

$T=\frac{F \times 1000 \times D}{2 \times 6 \times i^{2}}$,

where $D$ is the diameter of locomotive gear, and we assume there are six axles on locomotive.

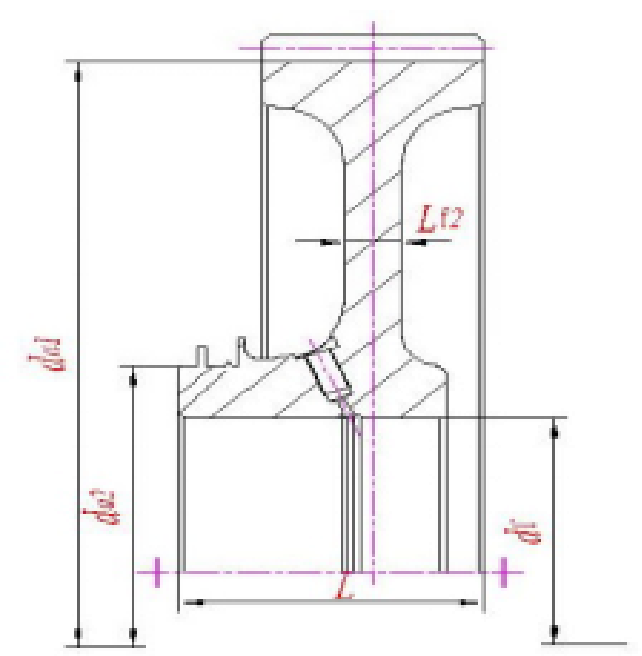

Fig. 2 Cross-sectional view of the driven gear

\subsection{Given conditions}

Gear tooth root diameter is $d_{a 1}=743.47 \mathrm{~mm}$. Gear-shaft combined diameter is $d_{f}=224 \mathrm{~mm}$. Theoretical combined length is $L=140 \mathrm{~mm}$. Locomotive starting traction is $F=500 \mathrm{kN}$. The shaft is a solid structure that is made of AAR M101-F steel. The gear material is 18CrNiMo7-6. The helix angle is $\beta=0$. The yield strength of the gear is $\sigma_{s a 1}=785 \mathrm{MPa}$. The yield strength of the axle is $\sigma_{s a 2}=340 \mathrm{MPa}$. The elastic modulus of the gear and the axle is $E_{a}=206000 \mathrm{MPa}$, the Poisson's ratio is $v=0.3$, and the friction coefficient is $\mu=0.14$.

As shown in Fig. 2, the theoretical combined length $L$ is divided into two parts according to the structure of the gear: $L_{f 1}$ and $L_{f 2}$, where

$L_{f 1}=$ connect length of axle $(L)$-web thickness $\left(L_{f 2}\right)$

$=140-32=108 \mathrm{~mm}$;

$L_{f 2}=$ web thickness $=32 \mathrm{~mm}$.

\subsection{The minimum effective interference}

The interference of the joint is the sum of the diameter variations of the containment component and the contained component, and the calculation of the assembly interference can be obtained from Eq. (2):

$$
\delta_{e}=P_{f} d_{f}\left(\frac{c_{a}}{E_{a}}+\frac{c_{i}}{E_{i}}\right),
$$

where $P_{f}\left(P_{f \min }, P_{f \max }\right)$ is the minimum contact pressure required to transmit torque and the maximum contact pressure that prevents the coupling from plastic deformation, $\mathrm{MPa} ; E_{a}, E_{i}$ is the elastic modulus of the gear and shaft individually, $\mathrm{MPa} ; c_{a}$ and $c_{i}$ are the coefficients referenced by gears and shafts.

$$
c_{a}=\frac{1+\left(\frac{d_{f}}{d_{a}}\right)^{2}}{1-\left(\frac{d_{f}}{d_{a}}\right)^{2}}+v_{a}, c_{i}=\frac{1+\left(\frac{d_{i}}{d_{f}}\right)^{2}}{1-\left(\frac{d_{i}}{d_{f}}\right)^{2}}-v_{i}
$$

Due to the unique structure of the locomotive driven gear, with the formulas above, when, $c_{a 1}=3.82, c_{a 2}=1.49$ using different value of $d_{a 1}$ and $d_{a 2}$. The actual contact length can be obtained from Eq. (3):

$L=L_{f 1}+L_{f 2} \frac{c_{a 1}}{c_{a 2}}$.

Then the minimum contact pressure of the improved algorithm is expressed as Eq. (4): 
$P_{f \min }=\frac{\left[F^{2}+\left(\frac{2 T}{d_{f}}\right)^{2}\right]^{\frac{1}{2}} K}{\pi L d_{f} \mu}=36.51 \mathrm{MPa}$.

We obtain $\delta_{\text {emin }}=0.164 \mathrm{~mm}$.

\subsection{The maximum effective interference}

The maximum contact pressure that could prevent the coupling from plastic deformation should be the smaller one of the maximum contact pressures of the enveloping part and that of enveloped part, which can be expressed as Eq. (5):

$$
P_{f \text { max }}=\min \left\{P_{f a \max }, P_{f i \max }\right\},
$$

where

$$
P_{f i \max }=\frac{d_{f}^{2}-d_{i}^{2}}{2 d_{f}^{2}} \sigma_{s i}, P_{f a \max }=\frac{1-\left(\frac{d_{f}}{d_{a}}\right)^{2}}{\left[3+\left(\frac{d_{f}}{d_{a}}\right)^{4}\right]^{1 / 2}} \sigma_{s a} .
$$

Due to the unique structure of the enveloping parts, as mentioned above, $d_{a}$ is divided into two parts: $d_{a 1}$ and $d_{a 2}, P_{\text {famax } 1}=190.9 \mathrm{MPa}$, and $P_{\text {famax } 2}=411.5 \mathrm{MPa}$. To meet the security requirements of the coupling, select $d_{a 2}$ to calculate $P_{f \max }$, which comes to be $170 \mathrm{MPa}$.

The maximum interference is expressed as Eq. (6):

$$
\delta_{e \max }=P_{f \max } d_{f}\left(\frac{c_{a}}{E_{a}}+\frac{c_{i}}{E_{i}}\right) .
$$

In order to ensure the security of the interference fitting and considering the monotonicity of the interference calculation function, $c_{a 2}$ is taken as the referenced coefficient of the enveloping part, we obtain the value of $\delta_{\text {emax }}$ to be $0.406 \mathrm{~mm}$.

\subsection{Determination of the amount of interference and comparison verification}

The stress concentration will occur at the root of the gear when the gear is working. A large value of interference fit stress tends to produce tooth root crack, which leads to tooth fracture. The stress of tooth root can be reduced by decreasing the amount of interference fit. Therefore, the above factors should be taken into consideration when selecting the maximum interference and the maximum effective interference should be left with enough security allowance.

The basic interference is expressed as Eq. (7):

$\delta_{b}=\frac{\delta_{e \max }+\delta_{e \min }}{2}=0.285 \mathrm{~mm}$.
The basic deviation code of the fit is determined by the basic interference and combined diameter calculated above. The hole-based system $\mathrm{H} 7 / \mathrm{u} 6$ is selected in this situation. According to the code GB/T1800.4-1999 (National Machinery Industry Administration Standard of China), the final minimum interference is determined to be $0.212 \mathrm{~mm}$ and the maximum interference is $0.287 \mathrm{~mm}$ (National Machinery Industry Bureau, 1999).

Since the locomotive wheel and the driven gear are both web structures, reference machine wheel pair assembly technical conditions for the recommended value of the overall silicon steel wheel interference: interference/combined diameter $=0.9 \% \sim 1.4 \%$, therefore: minimum interference $\delta_{\min }=224 \times 0.9 \%=0.2016 \mathrm{~mm}$, maximum interference $\delta_{\max }=224 \times 1.4 \%=0.3136 \mathrm{~mm}$. Using the standard GB/T 15755-1995 "The calculation and selection of cone interference fits" method, the driven gear of the locomotive is used as the standard cylinder to calculate the maximum, minimum and basic interference. The basic deviation band is calculated by using the base hole. With $\mathrm{H} 7 / \mathrm{t} 6$. The specific results are shown in Table 1 (GB/T 5371-2004 (National Technical Committee for Product Size and Geometric Specifications, 2004); GB/T 15755-1995 (Ministry of Machinery Industry of the People Republic of China, 1995)).

It can be seen that the calculation method of $\mathrm{GB} / \mathrm{T}$ 15755-1995 comes to a smaller value for the interference of the web structure which cannot meet the design requirements. The interference calculated by our improved algorithm meets the range requirements for the standard recommended values, and the tolerance accuracy is higher

Table 1 Comparison of the calculation of the interference amount $(/ \mathrm{mm})$

\begin{tabular}{lccc}
\hline Interference & $\begin{array}{c}\text { Original } \\
\text { algorithm }(/ \mathrm{mm})\end{array}$ & $\begin{array}{c}\text { Improved } \\
\text { algorithm }(/ \mathrm{mm})\end{array}$ & $\begin{array}{c}\text { Standard } \\
\text { recommendation } \\
(/ \mathrm{mm})\end{array}$ \\
\hline $\begin{array}{l}\text { Minimum } \\
\text { required } \\
\text { interference }\end{array}$ & 0.054 & 0.164 & - \\
$\begin{array}{l}\text { Maximum } \\
\text { allowable }\end{array}$ & 0.386 & 0.406 & - \\
$\begin{array}{l}\text { interference } \\
\text { Basic } \\
\text { interference }\end{array}$ & 0.22 & 0.285 & - \\
$\begin{array}{l}\text { Selected } \\
\text { minimum }\end{array}$ & 0.134 & 0.212 & 0.2016 \\
interference & & & \\
$\begin{array}{l}\text { Selected } \\
\text { maximum } \\
\text { interference }\end{array}$ & 0.209 & 0.287 & 0.336 \\
\hline
\end{tabular}


this way (EN 13260:2009+A1:2010 (European Committee for Standardization (CEN), 2010)).

\section{Finite element analysis of the interference fit}

In recent years, the finite element method has been introduced into the stress analysis of interference fit, providing a method for its design, selection and verification. In this paper we use ANSYS software to carry out the finite element analysis of the model. Due to the symmetry of the axle structure and the load distribution, the finite element model uses $1 / 4$ of the overall model to improve the calculation efficiency, and the gear structure is simplified as following: removing small chamfer, removing the teeth and use the root circle as the outer diameter of the containment. The eight-node hexahedron solid element Solid185 is used for meshing, and a face-to-face contact is established between the inner hole of the gear and the outer surface of the axle. In the contact pair property setting, the friction coefficient is set to 0.14 , the regular penalty stiffness is 0.1 , and the contact stiffness is specified as an asymmetric matrix. Stress distribution on $1 / 2$ or the whole model can be observed via post processor. The finite element meshing model is shown in Fig. 3 (Joshi, 2018; Özel et al., 2005).

We select all nodes on the axle axis to set the freedom to be full constraint, to simulate the structural boundary state of the gear assembly state. The stress at the minimum interference of the axle of $0.212 \mathrm{~mm}$ and the maximum interference of $0.287 \mathrm{~mm}$ is solved by the finite element calculation. The results are shown in Fig. 4 (Ramanan et al., 1999).

In order to verify that the contact force can effectively transmit the moment when the interference is at its minimum value, the Von Mises stress (Fig. 4) and the contact stress (Fig. 5) under this condition are calculated respectively. The maximum Von Mises stress is $173.617 \mathrm{Mpa}$, and the minimum contact stress is $50.3941 \mathrm{Mpa}$, which is greater than the minimum combined pressure $P_{\text {fmin }}$ required for transmitting torque: $36.51 \mathrm{Mpa}$. Therefore, the minimum value of interference $0.212 \mathrm{~mm}$ meets the design requirements of effective transmission torque (Jin et al., 2006; Zhang et al., 2000).

To verify that the axle material does not plastically deform when the shaft is assembled at maximum interference, the Von Mises stress (Fig. 6) and the contact stress (Fig. 7) under this condition are calculated respectively. The maximum Von Mises stress is $208.122 \mathrm{Mpa}$, which is less than the allowable stress of the gear and the shaft, the maximum contact stress occurs at the end of the inner hole of the hub, its maximum value is $245.808 \mathrm{Mpa}$,

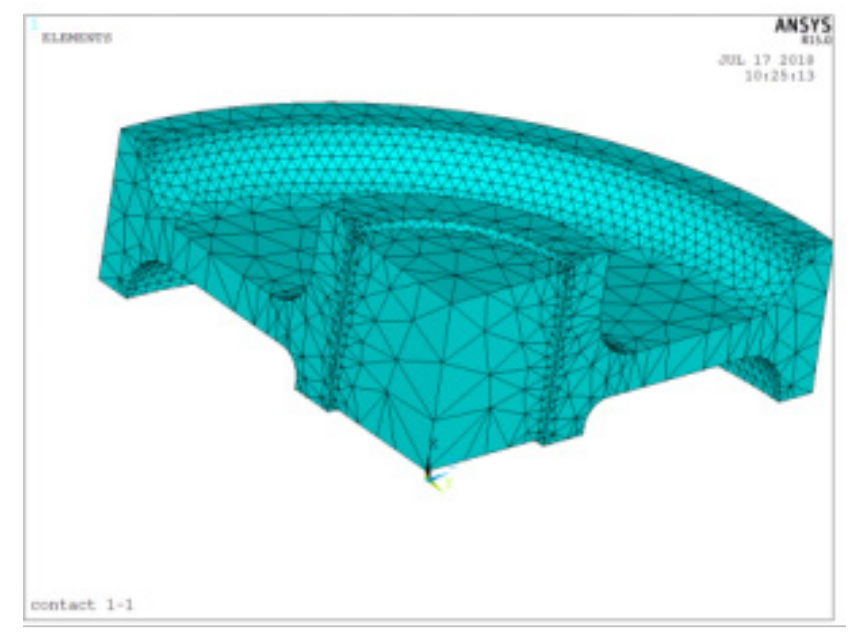

Fig. 3 Finite element 3D model

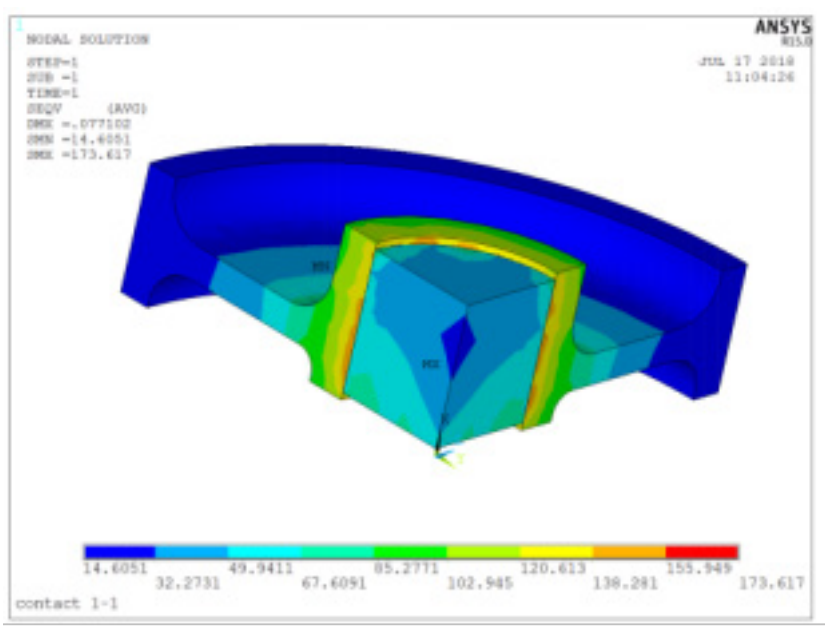

Fig. 4 Equivalent stress at minimum interference

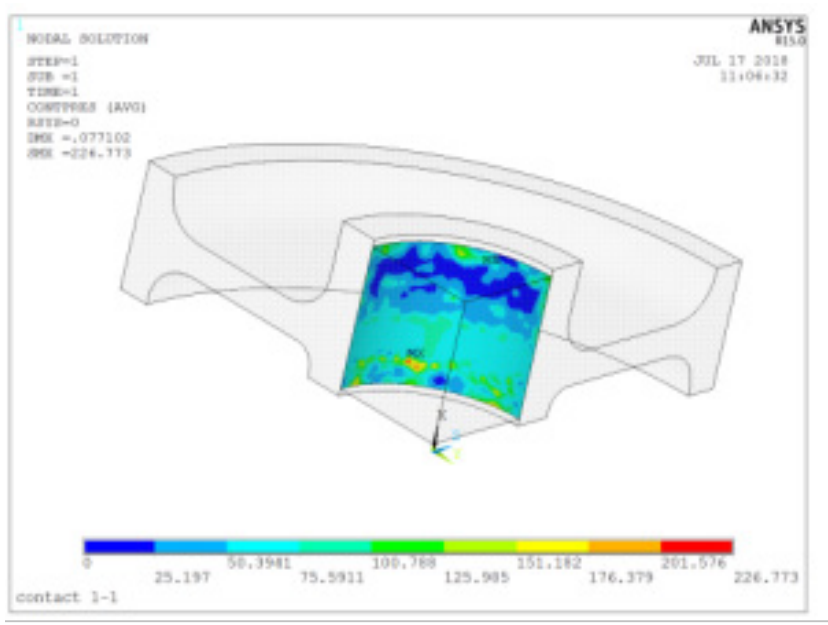

Fig. 5 Contact stress at minimum interference

which is smaller than the theoretical maximum allowable joint strength $P_{\text {famax } 2}: 411.5 \mathrm{Mpa}$. Therefore, the maximum interference value $0.287 \mathrm{~mm}$ satisfies the requirements for the plastic deformation of the axle material. 


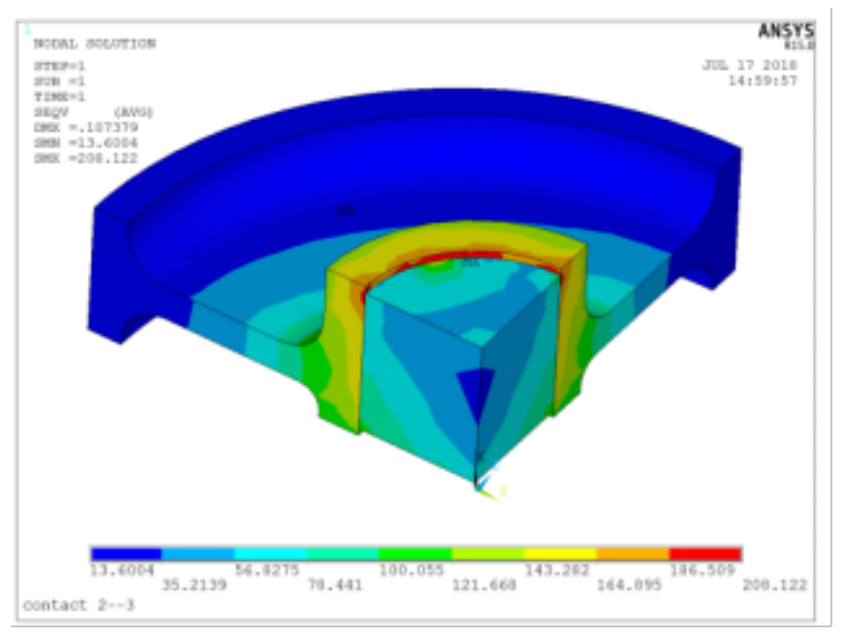

Fig. 6 Equivalent stress at maximum interference

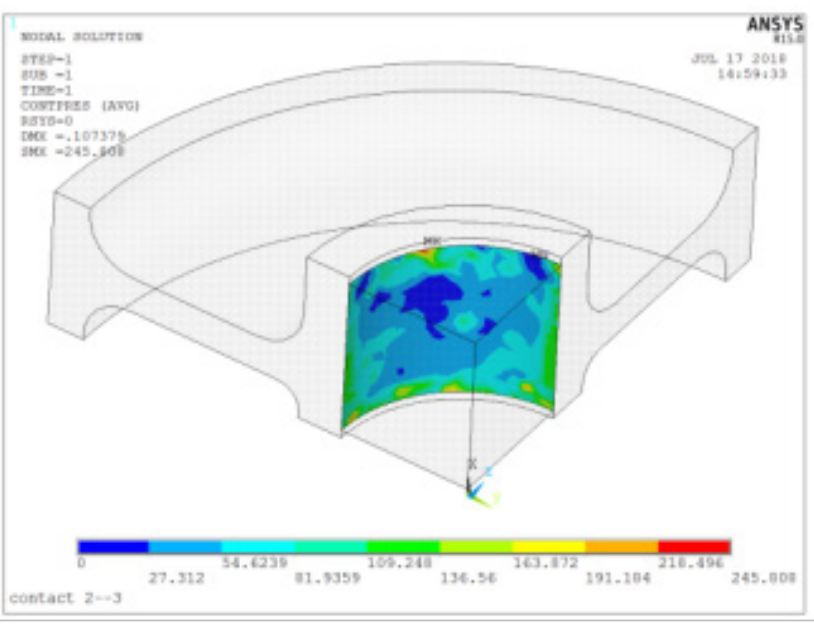

Fig. 7 Contact stress at maximum interference

\section{Gear press fit and back pressure test}

After design and production according to the final determined interference, the driven gear and the shaft are assembled by oil injection (Fig. 8). Back pressure test is applied after press-fitting, referring to the handbook Machine Wheel Assembly Technology Conditions. The assembly quality of oil-filling is measured according to pattern of the assembly curve. The interference and the surface quality are the main factors affecting the assembly quality. A larger or smaller interference would affect the pattern of the assembly curve. The assembly curve is one of the key indicators for the evaluation of the interference. A decent pressure curve should be a pattern that the pressure gradually increases with the increase of the pressing distance when the oil is not injected, and the pressure gradually decreases with the increase of the pressing distance after the oil filling. The pressing force reaches its minimum value at the end of the curve and is not more than $196 \mathrm{kN}$ (European Committee for Standardization (CEN), 2010).

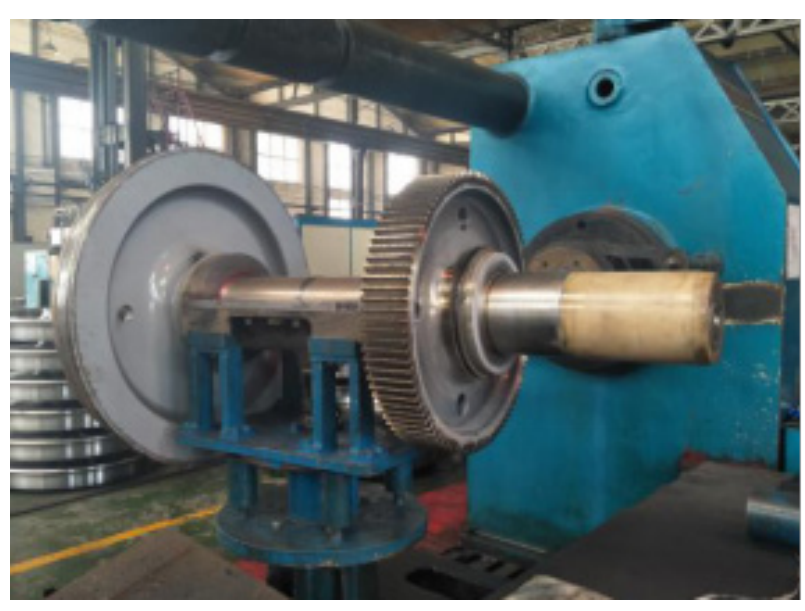

Fig. 8 Gear press test

It can be seen from the press-fit curve of Fig. 9 that the initial section of the curve is approximately linear. After reaching the maximum, the oil pressure is dropped slowly. Due to the influence of the oil-filled groove of the shaft, the press-fit curve has a small fluctuation, and then the curve gradually approaches zero. The pressure pattern satisfies the standard requirements of press-fit process. The pressing force at the end is less than $196 \mathrm{kN}$, indicating that the surface quality is decent, and the interference are set reasonably.

After the gear is installed in the correct position, the back-pressure test is performed in an equilibrium condition. The gear is supposed to keep still until the back-pressure reaches the minimum value $P_{p}$. This method is commonly used to verify the connection reliability of the interference.

After gear assembly, the gear back pressure test is carried out. The back-pressure test is performed after the gears assemble. As shown in Fig. 10, according to the standard requirements, the back-pressure $P_{p}$ is set to be $1213 \mathrm{kN}$ for $10 \mathrm{~s}$. There is no relative displacement between the gear hub and the shaft. The back-pressure curve is shown in Fig. 11. The straight horizontal line only has a pressure light drop in the end, indicating that the back pressure is stable, the contact surface is in good condition, and the interference is reasonably designed.

\section{Conclusions}

The traditional calculation method for the interference cannot meet the design requirements of the traction plate web structure. In this paper an improved algorithm combining the classical elastic mechanics and finite element segmentation is proposed. By comparing the calculation results obtained by the improved algorithm with the traditional method, we can see that the interference obtained by the improved algorithm is closer to the recommended value. 


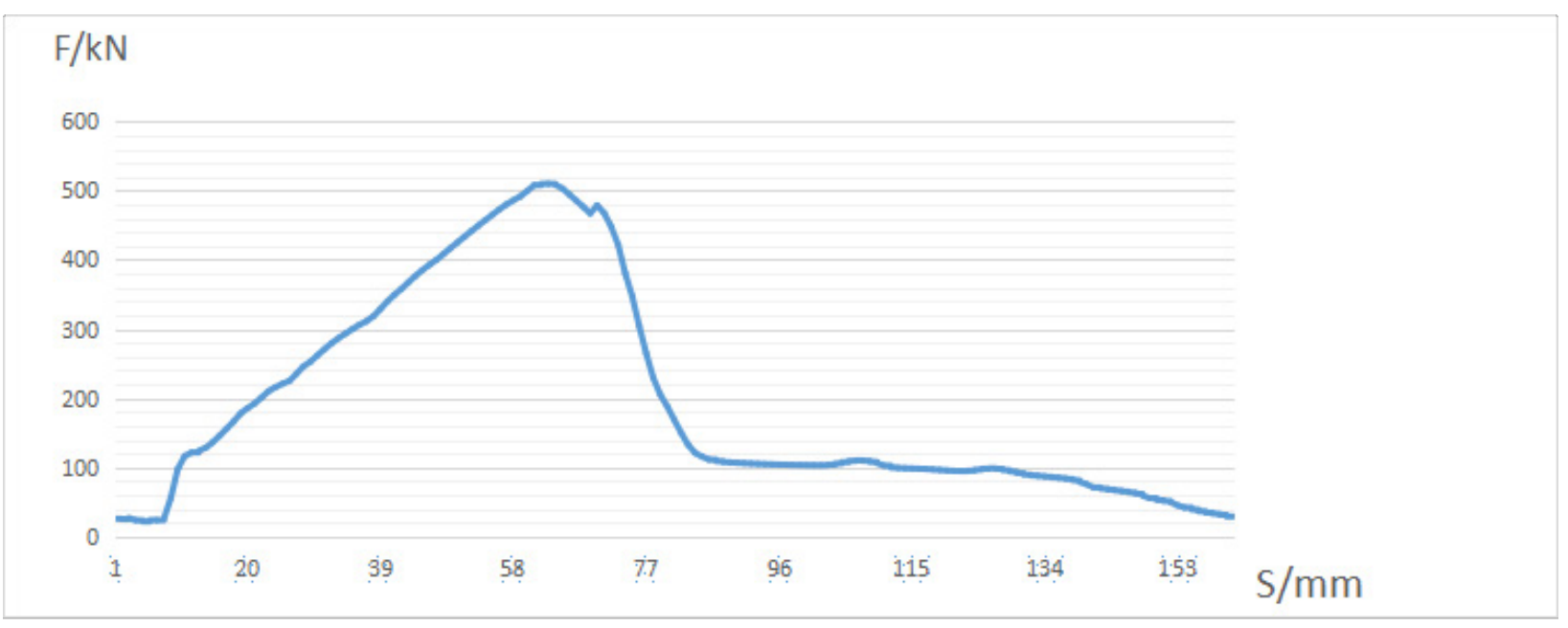

Fig. 9 Gear press curve

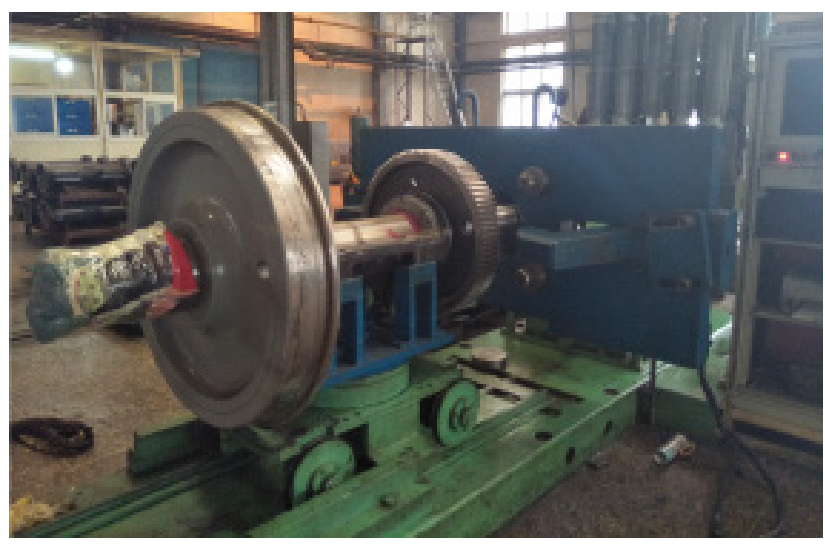

Fig. 10 Gear back pressure test
The finite element simulation software gives the minimum interference to be $0.212 \mathrm{~mm}$ and the maximum to be $0.287 \mathrm{~mm}$, which both satisfy the requirement of the traction torque transmission and stiffness of the joint. Gear press fit and back pressure experiments are performed to evaluate the reasonability of the interference calculated by our improved algorithm. The results show that the designed interference is reasonable, verifying that our interference improvement algorithm is suitable for the design of the web structure and provides a positive and effective guide for design engineers.

\section{Acknowledgements}

The project presented in this article is supported by Science and technology research and development foundation of China Railway (No. 2017J009-H).

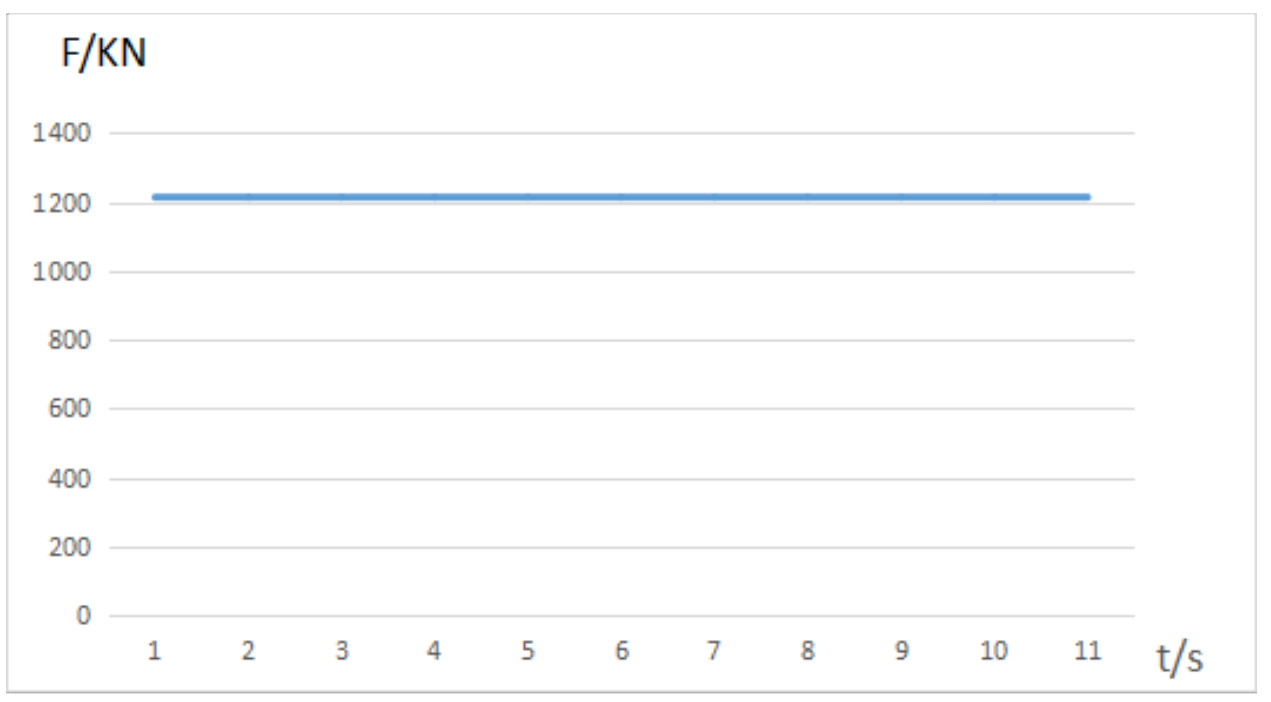

Fig. 11 Gear back pressure curve 


\section{References}

European Committee for Standardization (CEN) (2010) "EN 13260:2009+A1:2010 Railway applications - Wheelsets and bogies - Wheelsets - Product requirements", European Committee for Standardization (CEN), Brussels, Belgium.

Eyercioglu, O., Kutuk, M. A., Yilmaz, N. F. (2009) "Shrink fit design for precision gear forging dies", Journal of Materials Processing Technology, 209(4), pp. 2186-2194.

https://doi.org/10.1016/j.jmatprotec.2008.05.016

Jin, X., Zhi-Jing, Z. (2006) "Calculating model of interference amount for miniaturized gear and shaft shrink fit", Journal of Beijing Institute of Technology, 15, pp. 138-143.

Joshi, Y. (2018) "Gear Interference-Fit Joint Considerations and Design for the Resultant Tooth Distortion", SAE Technical Paper, Article number: 2018-01-1293.

https://doi.org/10.4271/2018-01-1293

Ministry of Machinery Industry of the People Republic of China (1995) "ICS 21.010, GB/T 15755-1995 圆雉配合的计算与选用" (The calculation and selection of cone interference fits), State Bureau of Quality and Technical Supervision (SBQTS), Beijing, China. (in Chinese)

National Machinery Industry Bureau (1999) "ICS 17.040.10, GB/T1800.4-1999极限与配合标准公差等级和孔、轴极限偏差表." (Limits and fits Tables of standard tolerance grades and limitdeviations for holes and shafts), State Bureau of Quality and Technical Supervision (SBQTS), Beijing, China. (in Chinese)
National Technical Committee for Product Size and Geometric Specifications (2004) "ICS 17.040.10, GB/T 5371-2004 过盈配合的计算和选用, , 中国标准化管理委员会" (Limits and fits. The calculation and selection of interference fits), General Administration of Quality Supervision, Inspection and Quarantine of the People Republic of China, China National Standardization Administration Committee, Beijing, China. (in Chinese)

Özel, A., Temiz, Ş., Aydin, M. D., Şen, S. (2005) "Stress analysis of shrink-fitted joints for various fit forms via finite element method", Materials \& Design, 26(4), pp. 281-289.

https://doi.org/10.1016/j.matdes.2004.06.014

Ramanan, L., Krishna Kumar, R., Sriraman, R. (1999) "Thermomechanical finite element analysis of a rail wheel", International Journal of Mechanical Sciences, 41(4-5), pp. 487-505. https://doi.org/10.1016/S0020-7403(98)00078-2

Zhang, Y., McClain, B., Fang, X. D. (2000) "Design of interference fits via finite element method", International Journal of Mechanical Sciences, 42(9), pp. 1835-1850. https://doi.org/10.1016/S0020-7403(99)00072-7 